\title{
'FRESH OFF THE BOAT' AND THE MODEL MINORITY STEREOTYPE: A FOUCAULDIAN DISCOURSE ANALYSIS
}

\author{
Truong Minh Hang ${ }^{1, *}$, Phung Ha Thanh ${ }^{2}$ \\ 1_Faculty of English Language Teacher Education, VNU University of Languages \\ and International Studies, Pham Van Dong, Cau Giay, Hanoi, Vietnam \\ 2_Faculty of Linguistics and Cultures of English-speaking Countries, VNU University of Languages \\ and International Studies, Pham Van Dong, Cau Giay, Hanoi, Vietnam
}

Received 03 August 2018

Revised 25 September 2018; Accepted 28 September 2018

\begin{abstract}
This project studies how the American sitcom Fresh Off the Boat performs the model minority discourse. The performance, in line with the Foucauldian tradition of discourse analysis, is understood based on the networks of events and meanings that have rendered the model minority stereotype intelligible. The study informs that the model minority stereotype entered the discourse on Asian Americans through mainstream media's rationalization of Asian Americans' economic success in 1960s, marking a significant change in social perceptions of Asian Americans. It demonstrates that the discursive status of the stereotype has been conditioned by three power networks namely the black-white paradigm, the Asian American family, and the stereotype-based humor in American sitcoms. Fresh Off the Boat, the authors argue, participates effectively in shaping contemporary model minority discourse as it employs the three power networks in an approach more realistic and humane than mere oversimplification of Asian American experience.
\end{abstract}

Keywords: Asian American, model minority, television, Foucault, power network

\section{Introduction}

This study started with an interest in Asian Americans, a minority group that is at the same time underrepresented and subject to persistent stereotypes in American culture. Despite a rapid increase in demographics, along the history of American media, Americans of Asian descent have ranked the least likely among major ethnic minority groups to be cast as lead roles in mainstream television (Kim \& Kell, 2015). In the 1960s, the model minority image, portraying Asian Americans as highly

* Corresponding author. Tel.: 84-974397395 Email: minhhangtruong95@gmail.com ambitious and academically intelligent individuals who set an example as the 'superior' minority for other groups to follow, emerged as a prominent characterization. Since then it has become the most pervasive stereotype to be utilized by mainstream media to depict Asian Americans. As technology evolved and modern media platforms came to existence in the 2000s, Asian American public visibility has been strengthened (Hao, 2016). Among phenomena of success, the 2015 ABC's TV series Fresh Off the Boat, the first sitcom in twenty years to feature Asian American protagonists on primetime television, stands out. The pilot episode of the show was aired on February $4^{\text {th }} 2015$ and soon 
became the second-highest viewed comedy premiere of the quarter (Kissell, 2015). On Rotten Tomatoes, the first season has a $91 \%$ certified fresh approval rating. In May 2018, the series was renewed for a fifth season. While making an exhaustive use of the model minority stereotype, Fresh Off the Boat is regarded a charming family sitcom. It offers a rich site that would allow us to keep in touch with contemporary performances of Asian American identities in mainstream media.

The model minority stereotype and its embodiments, due totheirstatus asa widespread system of thought, from a Foucauldian perspective, qualify as a discourse. The key question of the present study is how the American sitcom Fresh Off the Boat, hereafter also referred to as $F O B$, performs the model minority discourse. Indeed, while discourse primarily refers to the sayable, it is the sayable about people and things, including objects of furniture, architecture, motion picture, etc. The objects of Foucauldian discourse analysis are not limited to verbal statements. $F O B$ is relevant to discourse analysis since its material arrangement exhibits a system of thought characteristic of the model minority discourse.

This study is built upon the Foucauldian tradition of discourse analysis that has taken shape in media studies since the 1990s. Accordingly, the following bearings define our endeavor.

Firstly, how $F O B$ performs the discourse is examined in relation with the networks of events and meanings that have rendered the model minority discourse intelligible, which are also called its historical conditions. For example, without discourses about race in American society, the model minority notion would be incomprehensible; thus, the discourses about race in American society are part of the historical conditions that have made the model minority discourse possible.

Furthermore, central to the study is the attempt to outline the power relations among different subjects produced by the model minority discourse, including American Asians, race, gender, family, success, etc. As an illustration, that parents act as the dominant figure to pressure their children to outperform peers in school is a notion belonging to the model minority discourse, from which we can say that the discourse has produced power relations between parents and children. We use the term 'power network' to characterize the model minority discourse and its constituents. As meanings effect power, a network of meanings is also a power network.

A Foucauldian discourse analysis, this humanities study does not involve quantitative descriptions of the ideologies and linguistic features of a systematically collected sample of statements in accordance with pre-selected theoretical frameworks. From the onset, $F O B$ has been known as a performance of the model minority discourse. The challenge for our humanities essay lies in establishing the historical conditions of the discourse and featuring the particularities of $F O B$ 's performance. We do not aim at a thorough investigation of the historical conditions of the discourse, but to study $F O B$, it is necessary for us to synthesize from accessible relevant artifacts narratives about the formation of the model minority discourse. A media product is successful not because it reproduces a wellaccepted way of thinking but because its particular execution works. Thus, apart from showing how $F O B$ conforms to the broad model minority discourse, our analysis of the show emphasizes its particularities, using examples from the first season.

Last but not least, our mode of inquiry 
entangles constant exposure to relevant materials, critical reflection, and meticulous language crafting. The research process in no way resembles clear-cut step-by-step procedures. What matters is not how the research process has happened but how informative, persuasive, and generative this essay can be.

To address the research problem, the body of this essay will develop into three parts. The first part presents an overview of the emergence of the model minority notion in 1960 s and its discursive developments until the 2010s. The second part demonstrates that the discursive status of the stereotype has been conditioned by three power networks namely the blackwhite paradigm, the Asian American family, and the stereotype-based humor in American sitcoms. It also offers a brief analysis of how the 1994 ABC's TV series All-American Girl, the precedent of FOB, executes the three power networks. Finally, the authors analyze FOB's performance of the model minority discourse, arguing that the sitcom participates effectively in shaping the contemporary model minority discourse as it employs the three power networks in an approach more realistic and humane than mere oversimplification of Asian American experience.

To our knowledge, while several scholarly works have studied how the memoir and sitcom version of $F O B$ represent Asian Americans (Yeh, 2016; Chen, 2017), none has been done in a Foucauldian tradition. Apart from providing a glimpse into how the model minority discourse persists in contemporary U.S., our study exemplifies a Foucauldian approach to critical media literacy. We propose that to be critical of media images involves understanding the historical conditions that have made them possible as well as the strategies they employ to participate or intervene in existing systems of meanings and power.

\section{An overview of the emergence of} the model minority notion in 1960 s and its discursive developments until 2010s

The model minority discourse would not be possible without stories about Asian Americans and their success. There is congruence between what is considered as factual accounts of Asian Americans and the contents of the model minority stereotype. Asian Americans are an ethnically diverse group who have arrived in the U.S. in vastly different conditions. Despite the stark differences in their initial contact situations and collectively little recognition in the mainstream culture, all Asian groups were able to have established a relatively firm economic stand in the American society after some time of settling in their new life (Healey, 2013). The phrase 'model minority' later made its first appearance in a New York Times article in January 1966 as a plaudit of "the efforts of Japanese Americans in their successful struggle to enter the mainstream of American life" (Petersen, cited in Osajima, 2005, p. 216). This was followed by a U.S. News and World report on the success of Chinese Americans, which also utilized the term as the overarching concept to denote qualities such as diligence, morality, and thrift. According to Wong and Halgin (2006), the model minority image typically presents Asian Americans as either small business owners or academically accomplished students who, in spite of struggles and hardship, show great perseverance to "own a piece of the American dream" (p. 38). For the first time, Asian Americans were displayed in an ostensibly favorable light, subtly neglecting all the 
past discrimination incidences in history, including the Chinese massacre of 1871 in Los Angeles, California-where approximately 20 Chinese immigrants were murdered by a mob of white men, or the Japanese internment camps during the 1942-1946 period-where hundreds of thousands of U.S. citizens of Japanese ancestry were forced to relocate to dilapidated camps after the Pearl Harbor attack, among others. The emergence of the model minority notion changed the rules of stereotyping Asian Americans. Negative stereotypes that convened adjectives such as illiterate, undesirable, full of filth and disease, and unassimilable withdrew so that positive ones came to the front.

The positive image, though bearing a certain degree of truth, was inevitably just the tip of the iceberg. One should be reminded that this new Asian American identity emerged amidst a specifically racially-sensitive era in American history, when the Civil Rights Movement was triggering intense debates around racial politics and challenging the Jim Crow system of racial segregation against African Americans. The model minority notion perpetuated by popular media in this historical context carried political implications that could act as a confutation to claims of a racist America. In this regard, Yamada (1981) and Osajima (2005) arrived at the same conclusion that the model minority stereotype did in fact disguise structural inequalities experienced by ethnic minority groups in this period and further illustrate a distorted image of a fair American society where everyone, irrespective of their skin color, is granted the same rights and opportunities to 'make it' in the New Land.

In the decades following the 1960s, representations revolving around the concept of model minority continued to pop up in major popular press publications, but the approach witnessed noticeable changes. To understand their significance, it is important to note that the notion of model minority was frequently criticized for the way it narrows the Asian American identity into 'pan-ethnicity' - that is, instead of being viewed as an ethnically diverse group consisting of different backgrounds, Asian American immigrantsespecially those belonging to the second generation onwards, tend to feel that their unique cultural heritage is often neglected (Park, 2008). During the 1980s, various articles began to acknowledge the dynamic nature of the Asian American population (Bell, 1985; Barringer, 1990). As the 1965 Immigration Act made Asians become the fastest growing minority in the country, it was only natural that the Asian American demographics was broadened to include Korean, Vietnamese, and other foreign-born Asians, rather than only Japanese and Chinese. Another change in the narratives involved the realization of a negative by-product created by the model minority stereotype: Lee (1994) points out that the 'model' label places tremendous pressure on Asian American students to strictly fulfill their parents' expectations and thus, propels them to focus too much on academic work while overlook social skills. Among other criticisms, these two new insights display "a greater recognition of the complexities and critiques associated with the model minority thesis" (Osajima, 2005, p. 218).

Since its inception, the major propositions of the model minority stereotype have stayed stable. Its discursive developments since the 1990s up to now include more visibility in American television and a change in ownership. In the media landscape of the U.S., as a general situation, Asian Americans have endured underrepresentation. The situation is particularly grave when it comes to mainstream television. While it is possible 
to say that the dominant image of Asian Americans in television is that of the model minority, we derive this conclusion mostly from brief appearances of Asian Americans, especially in TV commercials. To be specific, studies conducted to analyze the portrayals of different ethnic minorities in the U.S. advertisements reveal that Asian Americans, in the rare occasions when they are featured, appear mainly in technology-related product placements (Mastro \& Stern, 2003), which correlates with the stereotype that Asians are tech-savvy nerds. Ethnically Asian actors are also seen predominantly in a business setting and hardly ever in a social or family relationship (Coltrane \& Messineo, 2000). This kind of representation hints at an emphasis on the work ethic deemed a typical model minority characteristic. The pool of American movies and series with Asian leads has been very limited. The first sitcom in American television history to assign an all-Asian cast to be protagonists was the 1994 ABC's TV series All-American Girl, hereafter also referred to as $A-A G$. Despite being expected to be a groundbreaking Asian American debut show, $A-A G$ received numerous unfavorable reviews and had to be cancelled after only one season. The series features a Korean American family and constructs its main plot around the rebellious daughter Margaret Kim, who forcefully rejects the model minority identity. The show suggests that the model minority stereotype went from a product of white Americans to a set of characteristics that Asian Americans claim to characterize Asianness.

American audience had to wait for more than 20 years for the second sitcom with an all-Asian cast, the 2015 ABC's TV series Fresh Off the Boat. This time, the model minority stereotype is obviously the frame of the show. $F O B$ is created in a decade where Asian Americans have achieved a certain degree of success in their quest for more representation in mainstream media. This was made possible by the growing popularity of superstars like Ryan Higa, Kevin Wu, Michelle Phan, to name a few, on the new influential digital platform of YouTube during the 2007-2013 era. Ever since this period, a 'revolution' has occurred in the diversity of the major American broadcast networks' shows: instead of employing conventional allwhite lead roles, approximately 30 percent of the series featured "a mostly non-white cast" or "non-white actors as co-leads" (Deggans, 2015). In the case of ABC (FOB's production company), the sitcom form adopted by this Disney-owned group seems to take a distinctive route: not only has $\mathrm{ABC}$ created prime-time series with protagonists being those of ethnic minority background, they have simultaneously included production teams-people conceiving the inchoate essence of a show - that encompass people of color. According to Paul Lee, ABC's former president, the key to their company's success lies in this inclusion of 'authentic voices', for this broadcast network believes only creators with real-lived experiences that truly resonate with the storyline can portray it under the most genuine light (Lynch, 2016). In this context, the model minority stereotype in $F O B$ is expected to attain a new status: it stands for real-life experience decisively claimed by Asian Americans themselves. The sitcom $F O B$ is inspired by the life of chef and food personality Eddie Huang and his memoir. The real-life Eddie Huang narrated the first season. He later made it clear that the show had veered off the authentic storyline in his memoir. His mordacious critique of the show's lack of authenticity suggests that a stereotype is unlikely to capture real-life experience adequately.

In summary, since its emergence in the 
1960 s, the model minority notion has persisted. However, the model minority as a discourse has gradually incorporated nuances about how the stereotype applies to Asian Americans and new forms of performance. We also notice that the model minority concept has received a lot of criticisms. The simplifying nature of the stereotype and its operations on relations among different racial groups and within the group have been recognized.

\section{Three power networks of the model minority discourse and All-American Girl}

For those who are concerned about the model minority stereotype, perhaps as soon as Asian Americans appear as well educated, intelligent, competitive, hardworking or successful in media, the stereotype is named. However, even the intelligibility of small details as the model minority is predicated on extensive systems of identification. The model minority as a general discourse is a huge system of materials and meanings. To take a closer look at the discourse, this study locates three power networks that have contributed to shaping the discourse in American media and are particularly important to make sense of sitcoms with multiple episodes. A brief analysis of the way the 1994 ABC's TV series All-American Girl performs the model minority discourse is included to illustrate the synthesis of the three power networks in the presence of the model minority stereotype as well as to provide points of comparison and contrast for appreciating $F O B$.

\subsection{The black-white paradigm}

To begin, the visibility of Asian Americans paradoxically relies on a paradigm that hints at their invisibility: the black-white paradigm. In introducing the black-white paradigm, this essay calls attention to the construction of
Asian American identities using black and white identities.

The black-white paradigm was originally a concept brought into existence by a series of historical accounts in the legal system of the U.S. The pioneering event involved the California Supreme Court's ruling in 1854 that classified Chinese Americans as American Indians - or Native Americans, after a murder-convicted white man appealed to the jury's judgment by claiming that the Chinese American witness in the case shall not have the rights to offer testimony against a white man. The convict's lawyer justified his argument by citing the anthropological hypothesis that Native Americans were descendants of Asian groups who migrated to the Americas over the Bering Straits, and thus the Chinese American witness must be considered a member of Native Americans, who, at the time, were disenfranchised of the right to give testimony in court.

The racial status of Chinese Americans was made even more perplexing as the state of Louisiana categorized them as white in 1860 , but by 1870 they were re-classified as Chinese. In 1927, the U.S. Supreme Court settled on the definition of the Chinese as nonwhite, hence propelling this group to be subjected to segregation under the Jim Crow legislation. It is worth remembering that a similar story of fluid identity could be told by several other ethnic minorities including Japanese Americans in California and Latino/as in Texas, and that in the instances where these non-black minority groups were assigned such manipulated racial labels, the underlying motive of the lawmakers had concerned the ultimate protection of whiteness and white privilege against people of color on the grounds of a black-white binary pattern detected from antecedent legal documents (Alcoff, 2006, p. 250). 
The black-white paradigm then could be understood as a notion that regards racial discourse in America as predominantly revolving around only two groups: the black and the white. The term became more widely accepted during the 1960s Civil Rights Movement when African Americans constituted 96 percent of the minority population, but soon faced scrutinizing criticisms from scholars of color for its oversimplification of a convoluted racial hierarchy. By neglecting the important history of civil rights narratives surrounding Latino/a, Asian, and Native Americans, the blackwhite binary rendered the racial complexities experienced by these groups almost invisible (Kim, 1999; Luna, 2003; Castagno, 2005). This dichotomy has constructed a racial image of an American society where "a very large white majority confronts a relatively small black minority, which has the effect of reinforcing the sense of inevitability to white domination" (Alcoff, 2003, p. 17).

On one hand, the black-white paradigm was mobilized to produce the model minority stereotype. On the other hand, emerging as a discourse produced by white Americans partly to reverse discrimination, the stereotype has added new elements to the black-white paradigm. In general, this stereotype places Asian Americans somewhat 'in the middle' of the black-white spectrum upon comparing "their proximity to white conservative values and economic success" (Kim, 1999, p. 2397). It is because of the 'elite' status of Asian Americans (they are considered 'more white' rather than 'more black') that the public often undermines the unique history of oppression against this ethnic minority group, and hence, refuses to take race-related problems associated with this group in a serious manner as they take African Americans. This consequence translates to the television world.
Stereotypical traits of the model minority are utilized to create commercials that sell these traits or to make jokes for the sake of entertainment. Attempts to narrate meaningful stories that reflect the experience of Asian groups are rare in U.S. media.

\subsection{Asian American family}

As a brief history of the model minority stereotype has been presented, this subsection focuses on a key element of the stereotype: a consistent family image. The family structure is a site to display relations between family members and to contest values. A model minority family is defined by the following interrelated power networks.

First, there is a marked emphasis on academic excellence as means of future socioeconomic success among school-aged youths. This is often seen as a result of the traditional Confucian values practiced by the majority of Asian families (Chou, 2008). To foster such success, parents are thought to be the driving force-placing tremendous expectations on children to excel academically, in hope that the achievements would secure the next generation of economic stability and social mobility in their future jobs (Goyette \& Xie, 1999). In terms of career orientation, there is also a biased attitude amongst parents towards high-ranked technical occupations such as doctors, lawyers, and engineers, as opposed to a climate of indifference in arts-related fields that are deemed frivolous and unrealistic (Goyette \& Xie, 2003). The focus on educational excellence sometimes puts children of Asian American households in the mentality of constant academic competition, which often creates a relationship of rivalry among the youths.

Second, the first-generation immigrants in a family are depicted as hard-working, driven individuals who have become successful technical workers or managers 
of small businesses. They achieve a level of economic mobility superior to that of other ethnic minorities and comparable to that of the dominant white population (Goyette \& Xie, 2003; McGowan \& Lindgren, 2006). The first generation, therefore, often acts as an epitome of perseverance and work ethic for their successors to emulate. In many cases, the second generation takes this role. The point is that parents must set an example of aspiration, work ethic, and success for their children.

Third, as a direct consequence of their economic accomplishment, both parents and children of a typical Asian American family are believed to be an exemplary case of successful assimilation into the mainstream community-living in the suburbs and harmoniously interacting with whites, which helps to legitimate the ideals of the American Dream (McGowan \& Lindgren, 2006). In this characteristic there exists a power relation between the model minority family and the outside world. Asian Americans are put on a pedestal when measured against other ethnic minorities and are regarded to be on a par with the dominant white groups.

When it comes to the last defining feature of a model minority family, patriarchy, we bear in mind that the model minority family is mostly understood as a typical Asian American family. Strictly defined, the model minority family is about the elements that are believed to represent Asian Americans' socioeconomic success. Nonetheless, since Asian Americans' socioeconomic success is explained by their family culture, all the cultural features characterizing a typical Asian American family are invoked when the model minority stereotype is brought to the table. The modern family is generally patriarchal, stressing the leading role of the husband and the father. This role is usually perceived as intensified in Asian American families.
These defining power networks of the model minority family are consistent in different media forms, allowing for easy recognition of the model minority stereotype.

\subsection{Stereotype-based sitcom humor}

The model minority stereotype does not need sitcoms for its discursive status. However, it is in tune with the sitcom genre, which typically bases its plot on a family structure and produces stereotype-based humor. American sitcoms have conditioned the model minority discourse by giving a form for its performances. This subsection seeks to describe the power network of stereotypebased humor in American sitcoms.

Ever since situation comedy made its debut on mainstream television during the $1950 \mathrm{~s}$, the genre has become the bread and butter of prime-time television. Compared to other forms of TV shows, sitcoms cost less to produce yet were far more sellable as reruns (Butsch, 2005). The success experienced by sitcoms is believed to be directly linked with the way they portray inferior statuses associated with society's long-standing stereotypes of women, blacks, and other minorities. Since the public has already been familiarized with these stereotypical images, the recurring character types embodying them become norms to viewers, on which writers and producers can depend to establish patterns of humor without having to give much explanation (Bowes, 1990; Butsch, 2005). Such strategy is particularly effective in a short form of drama like sitcom as the typical duration of an individual episode remains at only about twenty five minutes.

In the attempt to examine potential effects of racially stereotype-based jokes in sitcoms on audiences' perception of ethnic minorities, scholars often find it challenging to claim "whether viewers laugh at stereotyped 
minority figures or with them" (Bowes, 1990; Hall, 1990, as cited in Park, Gabbadon, and Chernin, 2006). However, more critical theorists claim that minority actors who take on roles having stereotypical traits associated with their own race stand a great chance of leaving a harmful impact on the climate of representation within their ethnic group. Specifically, the light-hearted, selfdeprecating portrayal could gradually translate to the naturalization of racial difference, which discourages audiences from critically engaging with racial discourses presented on mainstream media (Hall, 1997).

Alongside stereotype-based humor, patriarchy is another recurring element in the sitcom genre. In his in-depth analysis of the prominent trends dominating over three hundred series aired throughout the first five decades of sitcom history, Butsch (2005) concludes that there is a tendency to restrict the appearance of ethnic minority and women to roles equated with 'the fool' in the storyline - that is, the subordinate character who participates in the show's narratives with the central purpose of producing humor. By contrast, representations give spotlight to the white middle class, particularly middle class men, to emphasize their masculinity and dominance within the domestic sphere. This tradition of representation persists all through its span in prime-time television history and is capable of attracting a growing number of audiences. This fact proves that sitcoms are "preeminent examples of dominant culture, steadily presented to the largest population over the longest time" (Butsch, 2005, p. 112).

3.4. All-American Girl's performance of the model minority discourse

In $F O B$, there is a brief scene in which an Asian-American watching $A-A G$ pokes fun at its faults. Without doubt, $F O B$ is more successful, but $A-A G$ is not a lesser version of $F O B$. The two shows are interested in different issues and adopt contrasting approaches. $A-A G$ 's feminist intervention, the soul of the show, does not find an equivalent in $F O B$. The model minority stereotype is what Margaret Kim has to go against as she lives with her traditional Korean American family, not an encompassing order for all the protagonists as in $F O B$. While $F O B$ grapples with narrating real-life experience, $A-A G$ unabashedly presents a caricatured treatment of identities.

In $A-A G$, all-Americanness is predicated on an overemphasized Asianness. Stuart, Margaret's brother, plays the role of a doctor and a 'mama's boy' - the perfect moral standard in a family who upholds traditional Asian values while simultaneously achieves upward socioeconomic mobility in mainstream society. Margaret's mother takes great pride in Stuart's good-natured personality and obedience to his family's expectations whereas she is constantly in conflict with her Americanized daughter. Margaret Kim's character is in utmost opposition to her brother. Margaret wants "juicy American freedom, the kind of female bildungsroman that took place in nights out at the local club The Skank, a career in the music industry, and cute white boys with torn jeans and bad jobs" (Jung, 2014). Margaret rebels against an Asian family that appears insulated from American society as "an immaculately preserved corner of Asia" (Jung, 2014). In $A-A G$, 'Asian' and 'American' seem incompatible, just like patriarchy and feminism. Margaret abandons her familial culture to make room for the American culture. Her physical appearance, however, constantly reminds us that she is of Asian descent. While $A-A G$ shows that Asian Americans claim the model minority stereotype as representative of their original culture, Margaret's opposition to the identity 
in favor of American freedom suggests that the show, particularly the stereotype, is conceived from a white perspective and Asian Americans can be whitened.

As the Kim family is portrayed as a typical Asian American family, the characters are not specific enough to be realistic representations. This caused many to deem $A-A G$ racist. The expectation of authenticity might be irrelevant particularly in consideration to sitcom comedy. The show is clearly concerned with supplying the audience with a rendition of an Asian American family that meets stereotypical expectations rather than a realistic representation of Asian American experience. The rendition is done in such an extreme way that makes it a deliberate style instead of a failure to provide authenticity. To appreciate $A-A G$ one must read it on the level of stereotypes, which entails suspending the quest for realism. However, rigid stereotypes do not seem sustainable. The stereotype-based jokes go stale, which can be a problem of the show's stereotyping style or of bad script writing.

\section{Fresh Off The Boat's performance of the model minority discourse}

FOB tells the story of a Taiwanese American family trying to settle down in the whitedominated suburbs of Orlando, Florida after moving from Chinatown in Washington, D.C. to run their established Western steakhouse named Cattleman's Ranch. The Huang family consists of six members: Eddie Huang, his brothers Emery and Evan Huang, parents Louis and Jessica Huang, and grandmother, Grandma Huang. The family's closest neighbors are the age-mismatched white couple Marvin and Honey. Our critique of $F O B$ 's performance of the model minority discourse uses illustrations from the first season.
$F O B$ narrates the Huang family's experience heavily using formulas from the model minority stereotype and the sitcom form. It reinforces the stereotype, maintaining racial division and patriarchy. We argue that while FOB does not disrupt the networks of meanings and power that have shaped the stereotype and American sitcoms, the show produces a realistic, humane touch by featuring struggles and specificities. The realistic and humane conditions created by $F O B$ secure the show's success; however, stereotyping and the absence of disruptive scripts limit FOB's capacity to expand social horizons of sensibility.

\subsection{Struggles and the specificity of stereotypes}

In FOB's construction of AsianAmericanness on the model minority stereotype, the characters find themselves in and between black and white identities but do not try to relegate themselves to black or white positionalities. Their negotiation of black and white identities present stories of struggle that appear realistic and relatable. This approach is in contrast with $A-A G$ 's, where Stuart seems endowed with model minority traits without going through dilemmas and Margaret vehemently adopts a white American style to an extent that makes her strange to both Asian and non-Asian audience.

In the series, Eddie Huang, whose perspective functions as the main lens through which the story is told, establishes a clear association with the hip-hop subculture originating from the African American community. Eddie is a major hip-hop fan rooting for the Notorious B.I.G, 2Pac, LBC Crew and demonstrating his embrace of the music genre by wearing loose, baggy clothing and utilizing hip-hop slangs like "son", "fly", or "dope" in his speech attire. In this regard, author Eddie Huang, in an interview 
with Hot97 Radio Station in 2016, explained his choice of affiliating with black culture as a way to comprehend the racial scene in America and to construct his own identity as a second-generation Asian American immigrant: "[...] For anyone that was the outcast trying to understand their place and rule in America, you listen to hip-hop." His disclosure recalls the notion that black culture is somewhat representative of the status of all ethnic minorities in America (Lee, 2015). Nonetheless, there is a difference between downplaying non-black minority groups' experience by using the binary nature of the black-white paradigm and highlighting how Asian Americans relate to black culture. Randall Park, cast as Louis in the show, shared in an interview that he relates to young Eddie's outsider status through his association with hip-hop music as a kid growing up in the late 80s: "I loved it [hip-hop], I knew everything about it, I listened to everything I could get my hands on" (cited in Grierson, 2015). Eddie's resort to black culture is not to make himself black but to resist both Taiwanese and white culture. Eddie struggles with self-identity rather than easily accepting given options. The show's protagonist Eddie is not a natural model minority figure but one that is subject to the model minority intricacies laid out by his family.

Eddie's family fits entirely within the model minority stereotype. The Huang family is representative of the Asian assimilation into the mainstream community. However, the purpose is not to resemble white, and struggles against white are prominent. Upon the family's arrival in the new white-dominated neighborhood, narratives focus on describing how each member adjusts to the area. In the last episode of season one "So Chineez," the Huangs appear to have settled well into Orlando: Eddie becomes the school's student council president, Cattleman's Ranch attracts an increasing number of customers, and Jessica is on good terms with all the neighborhood women. Moreover, in their conversation with the friendly white neighbors Marvin and Honey about establishing membership in the North Orlando Country Club, Jessica finds it amazing that her family could actually be the first Asian American members, but what amazes her even more is how the white couple responds to her realization: "Oh, I didn't even think of that, you know sometimes I forget you guys are Chinese. [...] You guys are just like regular ol'Americans to us." Marvin consistently persuades Louis to come play at the tennis court and network with new people to help him expand the steakhouse. Presented with a valuable opportunity, Jessica unexpectedly confronts great fears of the family losing touch with their cultural roots, especially in terms of patriotic attitudes towards their homeland and appreciation of Mandarin. She goes to great lengths to change the family's daily routine in order to erase any sign of white culture, from dressing in full traditional Chinese ${ }^{1}$ clothing, cooking traditional Chinese meals, to sending the three brothers to a Chinese Learning Center two hours away from their house. Despite all these, at the end of the episode, she confesses to Louis: "I keep telling the boys to hold on to their identity, but I can 't even do it myself. They have me, Louis, I'm just a chipwich-eating American couch lady." Jessica's confession does not signify a complete surrender but a humble acknowledgement of the impossibility to remain purely Taiwanese. The Huang family achieves an Asian American status, a situation

1 The distinction between Taiwanese identities and Chinese identities has been the subject of heated debate. In this essay, instead of pointing to the People's Republic of China, 'Chinese' refers to the large civilization of which Taiwanese culture has long been considered a part. 
remarkably different from the Kim family's in $A-A G$. The Kim family shies away from Americanness, and Margaret's bold embrace of American identities tends to accentuate her lack of Americanness. In $F O B$, the model minority stereotype topples the wall between Asianness and Americanness, marking the recognizability of the Asian American as a group.

Definitely, the model minority status is a product of struggles. The Huangs' model minority traits might have originated from cultural traditions but are only present in complex struggles. The Huangs' journey to establish their new western steakhouse in Florida is a typical model minority story in that it highlights the parents' priority of the family's collective economic success over every other personal business. At times, the priority leads to possibility of vices. FOB uses these situations to produce humility and the courage to acknowledge one's truths and feelings.

In episode seven "Showdown at the Golden Saddle," a truth is revealed to viewers: the Huangs' Cattleman's Ranch Steakhouse is a knock-off version of the famous Golden Saddle franchise in Orlando. Louis confesses to Jessica that he stole the restaurant's confidential operation manual and made some alterations in order to create their own version of the 'wild West' steakhouse. Through Eddie's narration at the beginning: "When it came to providing for his family, he [Louis] would do whatever it took," viewers are introduced to the model minority script, but the whole episode is not only to emphasize the strong drive for success that Asian Americans have upon setting foot into the Promised Land. Louis and Jessica are shown embarrassed.

In episode three "The Shunning," the block party is a golden opportunity for the family to network with people in the neighborhood and promotes the restaurant. When Louis finds out that Jessica has made friends with Honey, the alleged home-wrecker that ruined her husband's first marriage, he warns Jessica that this friendship might have a negative effect on their restaurant's business because all the neighborhood women hold Honey in contempt. Having an internal conflict, Jessica ultimately decides to favor the sake of her whole family: "[...] You are right. It is not worth risking the future of the restaurant for somebody who I've just met because our number one priority should be the restaurant succeeding." In the block party, however, after seeing Honey being the only one to genuinely enjoy the Chinese stink tofu that she has carefully prepared, Jessica is moved and realizes that she does not have to pretend to turn a cold shoulder to Honey just because the family's business is at stake. Towards the end of the episode, Louis and Jessica could still find a way to spread Cattleman's Ranch's reputation a little farther yet manage to do so in a heartfelt, moralistic way.

Struggles characterize a minority status but are also common to humans. They provide substance for the audience to relate to. While framed by stereotypes, the struggles in $F O B$ occur as specific events. Comparing to $A-A G$, $F O B$ treats stereotypes with more specificity. Its advancement of specificity goes from crafting the contour of events to character building and environment setting.

Emery and Evan, Eddie's younger siblings, are model minority prototypes, and they are not the same. Evan is a star student who does everything right and obeys all the rules, simply for the sake of doing so. He has a more friendly relationship with his parents than with other kids. Emery, while upholding the image of a mama's boy, "blends in like a chameleon" and effortlessly socializes with 
his new friends. He acts like a stereotypical adult in his 20's, a ladies man who can get whomever he wants as a girlfriend. In model minority representations of Asian Americans, excellent academic prowess is usually associated with traits such as unsociability and awkwardness. Emery is stereotypical, but the $F O B$ team did make a creative move in shaping the character.

Furthermore, the Huangs are specifically Taiwanese/Chinese Americans. Although in real life the cast come from various Asian origins, it is clear that the characters are not Korean, Japanese or Indian. This is due to the use of representatives of Taiwanese/ Chinese culture. The Chinese stink tofu is an example. Constance Wu, who plays Jessica, in an interview by Jenny Zhang for The Lenny Interview in 2015, spoke about her initial fear of criticizing some of the show's details. Wu was then open about her request to make the show more specific, stating, "If you change the food to a 1,000-year-old black egg with tofu and scallions, it will be a little more specific, and specificity is just better for character, and it's more interesting than, say, tofu and rice" (Zhang, 2015). FOB is not undermined by complaints about its failure to be Taiwanese/Chinese. Unlike $F O B, A-A G$ is said to perpetuate the idea that all Asians are the same. $A-A G$ disappointed Korean American viewers, who found the briefly spoken Korean phrases essentially unintelligible.

To sum up, $F O B$ creates specific, relatable characters and stories, which, we believe, has sustained the show through seasons. Stereotypes arenotnecessarily distorted images of an existing reality. They are discursive units that organize social experience. FOB's performance of the model minority stereotype blurs the distinction between artificiality and authenticity. It is possible to commend that $F O B$ has been successful in narrating Asian
American experience from the perspective of Asian Americans. However, FOB's status as a sitcom laden with stereotypes does not allow it to make an arrogant claim of authenticity. Reality might be more harrowing. The real-life Eddie Huang yelled at the fact that "the show had bowdlerized his story, which included whippings by his father" (Nussbaum, 2015). He expressed frustration over ABC's approach, saying it advances "an artificial representation of Asian American lives" (Huang, as cited in Bacle, 2015). The sitcom was to suit a broad American audience, not to represent and satisfy the real-life Eddie Huang. There has not been any official statement coming from $\mathrm{ABC}$ or $F O B$ 's executive producers about the show's target audience, and the series has generated contrasting responses. Reportedly there have been numerous criticisms coming from Caucasian viewers claiming that $F O B$ 's characterization of Asian Americans is caricatured, racist even (Philip, 2014; Ferguson, 2015); on the other hand, Asian Americans, the ethnic group whose stereotypical representation is being treated as the main source of the show, mostly offer favorable reviews (Ferguson, 2015; Lui, 2015; Nguyen, 2015). In fact, many Americans of Taiwanese/Chinese ancestry claim they could relate to Eddie and his brothers on a personal level when seeing the boys being forced to attend classes at the Chinese Learning Center, a common experience for any Taiwanese/ Chinese American child growing up in the 1990s.

\subsection{Perpetuation of inequalities}

However specific its characters and stories are, $F O B$ 's reliance on stereotyping reproduces the power networks of the model minority image and American sitcoms. The model minority stereotype renders Asian Americans vulnerable to competition for academic excellence and 
economic success. Its loyalty to patriarchal nuclear family entails unequal relations between men and women, husband and wife, and parents and children. In alignment with the American sitcom tradition, ethnic minorities and women become 'the fool'. Without doubt, $F O B$ perpetuates inequalities.

Throughout the show, FOB employs a large amount of racial stereotype-based humor, especially through the way Eddie's mother Jessica Huang embodies virtually all of the characteristics of a model minority parent. Jessica exemplifies the 'tiger mom.' In the opening scene of episode two "Home Sweet Home-school," Jessica is shown more concerned with her sons' grades than a serious crime happening in the neighborhood. In the same episode, upon receiving Eddie's latest report card with straight A's results, to Eddie's surprise, his mother not only refuses to acknowledge his accomplishment but even proceeds to complain to the principal that "school is too easy." Since Eddie's middle school does not offer afterschool programs, Jessica voluntarily becomes her sons' homeschool teacher to assign them extra homework outside of the curriculum. The way Jessica plans out the future for her sons also reflects the way Asian American parents stereotypically underscore the significance of academic merits in upward mobility and encourage their offspring to aim at high-paying, technical jobs in the future. In episode twelve "Dribbling Tiger, Bounce Pass Dragon," when given the duty of directing Emery and Evan's school play, Jessica feels obliged to rewrite the script in a way that would make it meaningful enough to teach the children "life lessons so they'd be successful." The dialogues of the play, after Jessica's editing work, become serious conversations about her perceived values of jobs in the real world. She assigns Emery of the line "I'm studying to be a doctor, so I can make my parents proud," when Evan proudly claims "and I'm prepping for the bar exam so I can become a lawyer and have a stable income and health insurance." As FOB pokes fun at the tiger mom trope to elicit humor, Jessica Huang and the Asian parenting habits she performs are by no means objects of contempt. Respectful humor is a substance of egalitarian encounters; nevertheless, when humor comes from a specific stereotype, the contents of the stereotype tend to keep exerting their influence. A variety of structural inequalities are still at work.

For those with a feminist inclination, the promotion of competition and the packaging of cultural complexities into a racial box inherent in the model minority stereotype might not be as problematic as the reinforcement of patriarchal dominance. As $F O B$ popularizes the model minority stereotype, it puts women at disadvantage. Specifically, Louis is always more reasonable than Jessica. Thus, Jessica, while having a central role, somehow resembles 'the fool' in sitcom humor. Louis points out Jessica's overpowering manipulation of the school play's script. He convinces his wife to be more understanding of the difference between theirs and their sons' generation: "Oh, we never had the chance [to get involved in non-academic activities], Jessica, but isn't that why we work so hard, to give them the opportunity to do things that we couldn't do?" This conversation helps humanize both characters, but it is the wife's behaviors that need adjusting. Despite being portrayed as a bumbling character, Louis is the ultimate decision-maker: he is the one who decides to move out the entire family from their ethnic enclave in Washington D.C. to seek a new life in Florida. Being the breadwinner of a family of six, Louis nurtures and realizes the idea of opening his own restaurant so that they no longer have to work for Jessica's brother's business. Every detail of the Cattleman's 
Ranch Steakhouse, from location, setting, staff, to development strategies is determined by him. Even though Jessica plays the role of the tiger mom and rather aggressive wife, she is confined in the domestic setting as a stayat-home mother in the first half of season on. Louis is still the one in charge of governing the atmosphere and attitudes among all family members. The couple, however, shares a loving relationship.

In an article on The New Yorker, Nussbaum (2015) gives the following words to $F O B$ : "Fresh Off the Boat ${ }^{2}$ is unlikely to dismantle the master's house. But it opens a door." FOB sustains the unequal relations in the power networks of the model minority discourse. However, because of its humane scripts, we find a spirit of generosity that carries with it a promise to open up possibilities.

\section{Conclusion}

This study began with an interest in Asian Americans and then proceeded to a concern for the model minority stereotype, which had already attracted a plethora of criticisms. Criticizing a stereotype, an over-generalized belief about a category of people, seems overly easy. One just needs to reveal how the stereotype fails to account for all the group members, simplifies, distorts, or disguises reality. Departing from such a style of critique, this project models a critique of stereotypes that underscores their productive nature. Existing in and as discourse, the minority model stereotype not only represents Asian American experience but also reproduces power networks that lay out conditions for Asian American lives and those related to them. Suspending stereotypical perceptions is an ethical choice, but it is impossible for an individual to annul the effects of stereotypes.

${ }^{2}$ Originally written "Fresh Off the Boat"
Model minority stereotypes come from and produce large networks of meanings and power that individuals are caught in.

This essay is also a critique of a particular media work. An important event in presenting Asian Americans, $F O B$ is visible as an embodiment of the model minority stereotype. This reading is grounded in how the stereotype has been identified. Thus, we have brought into view networks of events and meanings constituting the intelligibility of the minority model discourse. At the same time, to say that $F O B$ performs the model minority discourse does not mean to assume that it simply activates something that has existed. For the show, to perform the discourse entails being creative and unique. $F O B$ would not survive without being specific in treating the model minority stereotype. It employs strategies to give a realistic and humane touch to its stereotype-based characters and stories. In this way, representations of Asian Americans in the show have been well accepted. The audience can relate to the characters and stories from their experience rather than just an understanding of the stereotypes. $F O B$ has continued to its fifth season. The series effectively participates in shaping contemporary model minority discourse, perpetuating racialization and patriarchy.

\section{Acknowledgements}

This study was inspired by the first author's participation in the course Topics in American Studies: Disadvantaged Peoples of the U.S. taught by Ms. Nguyễn Lê Hường, Division of Country Studies, Faculty of Linguistics and Cultures of English-speaking Countries, in spring 2016. Its initial form was a student graduation thesis paper finished in spring 2017 under the second author's guide. The authors would like to extend sincere 
thanks to family members and friends without whom the study would be impossible.

\section{References}

Alcoff, L. M. (2003). Latino/as, Asian Americans, and the black-white binary. The Journal of Ethics, 7(1), 5-27.

Alcoff, L. M. (2006). Visible identities: Race, gender, and the self. New York: Oxford University Press.

Bacle, A. (2015, April 8). 'Fresh Off the Boat' author Eddie Huang doesn't watch the ABC adaptation. Entertainment Weekly. Retrieved from http://www. ew.com/article/2015/04/08/eddie-huang-fresh-offthe-boat/

Barringer, F. (1990, n.d.). Asian population in U.S. grew by $70 \%$ in the 80 's. The New York Times. Retrieved from http://www.nytimes.com/1990/03/02/us/asianpopulation-in-us-grew-by-70-in-the-80-s.html

Bell, A. D. (1985, July 15). The triumph of AsianAmericans. New Republic. Retrieved from https:// newrepublic.com/article/76218/the-triumph-asianamericans

Bowes, M. (1990). Only when I laugh. In A. Goodwin \& G. Whannel (Eds.), Understanding television (pp. 128-140). London: Routledge.

Butsch, R. (2005). Five decades and three hundred sitcoms about class and gender. In G. Edgerton \& B. Rose (Eds.), Thinking outside the box: $A$ contemporary television genre reader (pp. 111-135). Lexington: University Press of Kentucky.

Castagno, A. E. (2005). Extending the bounds of race and racism: Indigenous women and the persistence of the black-white paradigm of race. The Urban Review, 37(5), 447-468.

Chen, C. W. (2017). Rotten bananas, hip hop heads, and the American individual: Teaching Eddie Huang's memoir Fresh Off the Boat and its tropes of literacy. Asian American Literature: Discourses and Pedagogies, 8, 5-25.

Chou, C. C. (2008). Critique on the notion of model minority: An alternative racism to Asian American. Asian Ethnicity, 9(3), 219-229.

Coltrane, S. \& Messineo, M. (2000). The perpetuation of subtle prejudice: Race and gender imagery in 1990s television advertising. Sex Roles, 42, 363-389.

Deggans, E. (2015, May 31). Racial diversity grows on network television, but will quality lag behind? Retrieved from http://www.npr.org/sections/ codeswitch/2015/05/31/408066158/racial-diversitygrows-on-network-television-but-will-quality-lagbehind

Ferguson, L. (2015, July 8). Why do sitcoms keeping it real offend you? IndieWire. Retrieved from https:// www.indiewire.com/2015/07/why-do-sitcomskeeping-it-real-offend-you-203202/

Grierson, T. (2015, February 11). Randall Park finds the funny in 'Fresh Off the Boat'. Backstage. Retrieved from https://www.backstage.com/interview/randallpark-finds-funny-fresh-boat/

Goyette, K., \& Xie, Y. (1999). Educational expectations of Asian American youths: Determinants and ethnic differences. Sociology of Education, 22-36.

Goyette, K., \& Xie, Y. (2003). Social mobility and the educational choices of Asian Americans. Social Science Research, 32(3), 467-498.

Hall, S. (1990). The whites of their eyes: Racist ideologies and the media. In M. Alvarado \& J. O. Thompson (Eds.), The media reader (pp. 7-23). London: British Film Institute.

Hall, S. (1997). The spectacle of the 'other.' In S. Hall (Ed.), Representation: Cultural representations and signifying practices (pp. 223-290). London: SAGE Publications.

Hao, K. (2016, October 13). YouTube has made AsianAmericans impossible for Hollywood to ignore. Next. Retrieved from https://howwegettonext.com/ youtube-has-made-asian-americans-impossible-forhollywood-to-ignore-be9c110e2be

Healey, J. (2013). Diversity and society: Race, ethnicity, and gender (5th Ed.). California: SAGE publications.

Jung, E. A. (2014, November 9). All-American Girl at 20: The evolution of Asian Americans on TV. Los Angeles Review of Books. Retrieved from https:// lareviewofbooks.org/article/american-girl-20 evolution-asian-americans-tv/\#!

Kim, J. Y. (1999). Are Asians black?: The AsianAmerican civil rights agenda and the contemporary significance of the black/white paradigm. The Yale Law Journal, 108(8), 2385-2412.

Kim, J., \& Kell, C. (2015, April 24). Asian-American Youtube celebrities aim to change perceptions, break into Hollywood. The Frame. Retrieved from http://www.scpr.org/programs/theframe/2015/04/24/42564/asian-american-youtubecelebrities-aim-to-change-p/

Kissell, R. (2015, February 11). Ratings: CBS wins Tuesday behind 'NCIS'; ABC's 'Fresh Off the Boat' is night's top comedy. Variety. Retrieved from https://variety.com/2015/data/ratings/ratings-cbsrolls-tuesday-behind-ncis-abcs-fresh-off-the-boatnights-top-comedy-1201431090/

Lee, S. J. (1994). Behind the model minority stereotype: Voices of high- and low-achieving Asian American students. Anthropology \& Education Quarterly, 25, 413-429.

Lee, C. (2015). 'Fresh Off The Boat' is huge for rap fans 
and Asian-Americans alike. Retrieved from http:// theconcourse.deadspin.com/fresh-off-the-boat-ishuge-for-rap-fans-and-asian-ameri-1683738079

Lui, R. (2015, February 8). Is new Asian-American show offensive? First look at 'Fresh Off the Boat'. $M S N B C$. Retrieved from http://www.msnbc.com/ $\mathrm{msnbc} /$ fresh-off-the-boat-new-asian-americanshow-offensive-first-look

Luna, E. (2003). How the black/white paradigm renders Mexicans/Mexican Americans and discrimination against them invisible. Berkeley La Raza LJ, 14, 225.

Lynch, J. (2016, February 17). In one of his last interviews as ABC Entertainment Chief, Paul Lee said he loves 'taking risks'. AdWeek. Retrieved from http://www.adweek.com/tv-video/one-his-lastinterviews-abc-entertainment-chief-paul-lee-saidhe-loves-taking-risks-169706/

Mastro, E. D. \& Stern, R. S. (2003). Representations of race in television commercials: A content analysis of prime-time advertising. Journal of Broadcasting \& Electronic Media, 47(4), 638-647.

McGowan, M. O., \& Lindgren, J. (2006). Testing the model minority myth. Northwestern University Law Review, 100(1), 331-377.

Nguyen, V. (2015, February 12). "Fresh Off the Boat" - New sitcom offers Asian American perspective. Northwest Asian Weekly. Retrieved from http:// nwasianweekly.com/2015/02/fresh-off-boat-newsitcom-offers-asian-american-perspective/

Nussbaum, E. (2015, March 9). Home cooking: Funny families on "Fresh Off the Boat" and "Black-ish." The New Yorker. Retrieved from https://www. newyorker.com/magazine/2015/03/09/homecooking-television-emily-nussbaum
Osajima, K. (2005). Asian Americans as the model minority: An analysis of the Popular Press Image in the 1960s and 1980s. In A. K. Ono (Ed.), A companion to Asian American studies (pp. 215 225). Massachusetts: Blackwell Publishing.

Park, J. H., Gabbadon, N. G., \& Chernin, A. R. (2006). Naturalizing racial differences through comedy: Asian, black, and white views on racial stereotypes in Rush Hour 2. Journal of Communication, 56(1), 157-177.

Park, J. Z. (2008). Second-generation Asian American pan-ethnic identity: Pluralized meanings of a racial label. Sociological Perspectives, 51(3), 541-561.

Philip (2014, December 14). 'Fresh Off the Boat': Thank you white people for pointing out its racism. You Offend Me You Offend My Family. Retrieved from https:/www.yomyomf.com/fresh-off-theboat-thank-you-white-people-for-pointing-out-itsracism/

Wong, F., \& Halgin, R. (2006). The "model minority": Bane or blessing for Asian Americans? Journal of Multicultural Counseling and Development, 34, 38-43.

Yamada, M. (1981). Invisibility is an unnatural disaster: Reflections of an Asian American woman. In C. M. \& G. A. (Ed.), This bridge called my back: Writings by radical women of color (pp. 35-40). New York: State University of New York Press.

Yeh, A. (2016). Changing the script: Social scripts as featured on 'Fresh Off the Boat' (Master's thesis). Retrieved from http://gradworks.umi. com/10/12/10128535.html

Zhang, J. (2015, October 30). The Lenny Interview: Constance Wu. Lenny. Retrieved from https:// www.lennyletter.com/story/the-lenny-interviewconstance-wu 


\title{
'FRESH OFF THE BOAT' VÀ THIỂU SỐ GƯO'NG MẪU: MộT NGHIÊN CƯUU DIỄN NGÔN THEO FOUCAULT
}

\author{
Trương Minh Hằng ${ }^{1}$, Phùng Hà Thanh ${ }^{2}$ \\ 1_Khoa Su phạm tiếng Anh, Truòng Đại học Ngoại ngũu, ĐHQGHN, \\ Phạm Văn Đồng, Cầu Giáy, Hà Nội, Việt Nam \\ 2_ Khoa Ngôn ngũu và Văn hóa các nước nói tiếng Anh, Truờng Đại học Ngoại ngũu, ĐHQGHN, \\ Phạm Văn Đồng, Cầu Giấy, Hà Nội, Việt Nam
}

Tóm tắt: Nghiên cứu này nhằm chỉ ra cách sitcom truyền hình Mỹ Fresh Off the Boat thể hiện diễn ngôn 'thiểu số gương mẫu'. Các tác giả sử dụng đường hướng phân tích diễn ngôn của Foucault, qua đó đặt hình ảnh khuôn mẫu thiểu số gương mẫu trong những mạng lưới sự kiện và nghĩa đã giúp nó tồn tại và trở nên hiểu được với nhiều người. Kết quả nghiên cứu cho thấy thiểu số gương mẫu được đưa vào diễn ngôn về người Mỹ gốc Á qua sự quảng bá hình ảnh thành công của nhóm trên truyền thông đại chúng vào những năm 1960, một dấu mốc về sự thay đổi của cảm quan xã hội về nhóm người này. Nghiên cứu cũng gọi tên ba mạng lưới quyền lực đan xen điều khiển diễn ngôn thiểu số gương mẫu, bao gồm: hệ hình trắng-đen, gia đình Mỹ gốc Á kiểu mẫu, và sự hài hước dựa trên hình ảnh khuôn mẫu trong sitcom Mỹ. Từ đó, các tác giả rút ra kết luận Fresh Off the Boat góp phần tạo ra diễn ngôn thiểu số gương mẫu của thời kỳ đương đại do nó tham gia vào ba mạng lưới quyền lực theo một cách nhân văn thay vì chỉ đơn giản hóa câu chuyện về người Mỹ gốc Á.

Tù khóa: người Mỹ gốc Á, thiểu số gương mẫu, truyền hình, Foucault, mạng lưới quyền lực 